\title{
Postoperative Surgical Complications of Live Unrelated Renal Transplants for Patients of End Stage Renal Disease Needing Renal Replacement Therapy
}

\author{
Raja Rizwan Ahmed1, Eyad Halabi2, Tarek Fathi2 and Mustafa Al-Mousawi2
}

\begin{abstract}
Objective: To evaluate the postoperative surgical complications of live unrelated renal transplantation (LURRT) done abroad for patients of end stage renal disease (ESRD) who needed renal replacement therapy (RRT) in an organ transplant centre.

Study Design: Descriptive, observational study.

Place and Duration of Study: Department of Renal Transplantation, Hamed Al-Essa Organ Transplant Center, Kuwait, from January 1993 to December 2015.

Methodology: This is descriptive and observational study in which data was retrospectively collected from medical records of the patients. All patients were selected who had been transplanted in various countries and admitted to this center for post-transplant care and follow-up in the period of 22 years and their surgical complications were noted. Data was analysed by SPSS 21. Nationalities and complications were noted and their percentages were calculated for the variables.

Results: A total of 423 patients (288 males (68\%) and 135 females (31.9\%), having mean age of 43 years) were transplanted in various countries. Most of these were Kuwaiti nationals $(n=224,53 \%)$. The post-transplant course was complicated by lymphocele in $25(5.8 \%)$, ureteral stenosis in $22(5.2 \%)$, urinary leak in $15(3.5 \%)$, incisional hernia in $14(3.3 \%)$ rare.

Conclusion: Due to inadequate living-related organ supply, many ESRD patients go to Third World countries for LURRT. Although, the risk of various complications is well established, this should be documented. Besides the ethical issues, overseas renal transplantation carries a high risk of unconventional complications.
\end{abstract}

Key Words: Live unrelated renal transplantation (LURRT), Surgical complications, End stage renal disease (ESRD).

\section{INTRODUCTION}

Renal transplantation is considered as a more desirable treatment option for patients who need renal replacement therapy (RRT) and is universally practised all around the world. There are various side effects of renal transplantation, but compared to dialysis, the survival of patients is comparatively better than the dialysis population. 1-3

According to World Health Organization (WHO), there are 91 countries where renal transplants are carried out. Around 66,000 kidney transplants, 21,000 liver transplants, and 6,000 heart transplants were performed globally in 2005. Although, transplantation offers the leading option for end stage renal disease (ESRD) patients, many of them do not have an opportunity for this type of treatment, mainly because of lack of organ supply.

${ }^{1}$ Department of Urology, The Kidney Centre Postgraduate Training Institute, Karachi, Pakistan

2 Department of Anesthesia, Hamid Al-Essa Organ Transplant Center, Sabah Health Region, Kuwait

Correspondence: Dr. Raja Rizwan Ahmed, Department of Urology, The Kidney Centre Postgraduate Training Institute, 179/9, Rafiqui Shaheed Road, Karachi, Pakistan

E-mail:rrrizwan@gmail.com

Received: March 19, 2018; Accepted: August 10, 2018
The shortage of organs is virtually a universal problem. In some countries, the development of a deceased organ donation programme is delayed due to legal, sociocultural and other factors. The use of living donors for kidney and liver transplantation is also practised, but the purchase and sale of transplant organs from live donors are prohibited in many countries. ${ }^{4}$ The shortage of an indigenous supply of organs has led to the development of the international organ trade, where potential recipients travel abroad to obtain the organs. In western countries, deceased organ donation has reached to a steady state thus a number of ESRD patients on transplant are on the waiting list and the list is increasing progressively day-by-day. ${ }^{5}$

Many ESRD patients, who do not have availability of living related donors, opt for other donor sources, including LURRT and considered it as the final option. Besides this, since many patients cannot find appropriate unrelated donors in their own countries due to multiple reasons (social, ethical and legal), they travel to other countries, mostly Third World, for their transplant, which also means commercial or paid transplantation, which is not always ethical. $6-10$

In 1987, the 40th World Health Assembly, due to the increased trade of human organs, initiated the preparation of the first WHO Guiding Principles on 
Transplantation, endorsed by the Assembly in 1991 (in resolution WHA44.25). This led to the passing of different laws to stop this illegal trade around the world. After a consultation process, which took many years, the 63rd World Health Assembly adopted Resolution (WHA63.22) on 21 May 2010, updated WHO Guiding Principles and many areas were identified to progress and legalise donation and transplantation practices. In May 2008, the Transplantation Society (TTS) and International Society of Nephrology (ISN) passed "Declaration of Istanbul" on organ trafficking and transplant tourism. Because of this, too many organisations and institutions around the world endorsed it.

However, despite these developments, unethical transplantation like LURRT is an ongoing process and transplant physicians and surgeons are frequently facing the problem of treating these renal transplant patients and their complications. Issues of renal transplantation can be classified as medical or surgical. Surgical complications involve vascular and urological complications, lymphocele, wound infection and herniation.

The aim of this study was to analyse the trends of renal transplants done abroad and their immediate or midterm postoperative surgical complications.

\section{METHODOLOGY}

This is a descriptive and observational study, Ethical approval was obtained from Hospital Reviewing Board of the Hamed Al-Essa Organ Transplant Center, Kuwait and carried out in the Department of Renal Transplantation from January 1993 to December 2015.

The Inclusion criteria involved all those patients who had been transplanted in various countries and admitted to our center for post-transplant care and follow-up in the period of 22 years. Renal transplants done in Kuwait during this period were excluded from the study.

A total of 423 patients were transplanted in various countries. These patients had different nationalities but $224(53 \%)$ of them were Kuwaiti nationals and had been dialysed in Kuwait, who traveled to multiple countries on their own initiative and returned after transplantation, while most of the patients were admitted to our clinic within the first four weeks after the transplantation.

The variables of the study were their original nationalities and countries where they went for their renal transplant and their early and late postoperative surgical complications.

Information about transplant operation arrangements, costs and hospital facilities were supplied by the patients. The preoperative clinical findings and laboratory results were obtained from the data provided by the patients.
Patients presenting with uneventfull post-transplant clinical course and normal kidney function with stable clinical and laboratory findings were followed at the outpatient clinic; whereas, those with medical and / or surgical complications were hospitalised.

After the arrival of each patient at the center, blood chemistry, urinalysis, creatinine clearance, electrocardiography, chest X-ray, plasma cyclosporine level, drainage fluid (if present) examinations, sputum and urine cultures, serological tests concerning cytomegalovirus, hepatitis $\mathrm{B}, \mathrm{C}$, herpes simplex, human immunodeficiency viruses (HIV), and thick and thin blood film examinations for plasmodia were carried out. Additionally, the scintigraphic and ultrasonographic examinations of the allograft, and percutaneous transplant biopsies were performed as needed. The data were collected retrospectively from patients' records and their surgical complications were noted.

Data were analysed using the Software Package for the Social Sciences (SPSS) version 21. Descriptive analysis of qualitative variables were described in the form of frequencies and percentages, while continuous variables were presented in terms of mean \pm standard deviation of normally distributed data.

\section{RESULTS}

Of the total 423 patients, there were $288(68 \%)$ males and $135(31.9 \%)$ females. The mean age was 42.9 \pm 13.008 (range 9 to 76 ) years. Out of these, highest number were done in Egypt 174 (41\%), followed by Pakistan 112 (26.5\%), India 55 (13\%) and Iran 27 (6.4\%), respectively (Table I).

Most of them were Kuwaiti nationals ( $n=224,53 \%)$. Rest included 85 (20\%) Egyptians and 32 (7.4\%) were Indians (Table II).

Table I: Various countries where live unrelated renal transplants occurred.

\begin{tabular}{lcc}
\hline Country & $\mathrm{n}$ & Percentage \\
\hline Egypt & 174 & $41 \%$ \\
Pakistan & 112 & $25.8 \%$ \\
India & 55 & $12.7 \%$ \\
Iran & 27 & $6.2 \%$ \\
Syria & 17 & $3.9 \%$ \\
Philippine & 14 & $3.2 \%$ \\
Iraq & 9 & $2.1 \%$ \\
Sri Lanka & 3 & $0.7 \%$ \\
USA & 3 & $0.7 \%$ \\
Jordan & 2 & $0.5 \%$ \\
Saudi Arabia & 2 & $0.5 \%$ \\
Lebanon & 1 & $0.2 \%$ \\
England & 1 & $0.2 \%$ \\
Bahrain & 1 & $0.2 \%$ \\
Thailand & 1 & $0.2 \%$ \\
France & 1 & $0.2 \%$ \\
\hline Total & 423 & 100 \\
\hline
\end{tabular}


Surgical complications included lymphocele in 25 $(5.8 \%)$, ureteral stenosis in $22(5.1 \%)$, urinary leak in 15 (3.5\%), and incisional hernia in 14 (3.2\%); as shown and other rare complication (Table III).

\begin{tabular}{lcc}
\multicolumn{3}{c}{ Table II: The nationalities of renal transplant recepients. } \\
\hline Country & $\mathrm{n}$ & Percentage \\
\hline Kuwait & 224 & $53 \%$ \\
Egypt & 85 & $19.6 \%$ \\
India & 32 & $7.4 \%$ \\
Pakistan & 21 & $4.8 \%$ \\
Saudi Arabia & 16 & $3.7 \%$ \\
Iran & 15 & $3.5 \%$ \\
Syria & 10 & $2.3 \%$ \\
Afghanistan & 3 & $0.7 \%$ \\
Jordan & 2 & $0.5 \%$ \\
Philippine & 2 & $0.5 \%$ \\
Sri Lanka & 2 & $0.5 \%$ \\
Sudan & 2 & $0.5 \%$ \\
Lebanon & 2 & $0.5 \%$ \\
Palestine & 2 & $0.5 \%$ \\
Bahrain & 1 & $0.2 \%$ \\
Bangladesh & 1 & $0.2 \%$ \\
Congo & 1 & $0.2 \%$ \\
Yemen & 1 & $0.2 \%$ \\
Italy & 123 & $0.2 \%$ \\
\hline Total & & 100 \\
\hline & 1 &
\end{tabular}

Table III: Postoperative surgical complications of transplanted patients.

\begin{tabular}{lcc}
\hline Postoperative complications & $\mathrm{n}$ & $(\%)$ \\
Lymphocele & 25 & $5.8 \%$ \\
Ureteral stenosis & 22 & $5.1 \%$ \\
Urinary leak & 15 & $3.5 \%$ \\
Incisional hernia & 14 & $3.2 \%$ \\
Wound infection & 12 & $2.8 \%$ \\
Renal artery stenosis & 6 & $1.4 \%$ \\
Graft thrombosis & 6 & $1.4 \%$ \\
Perigraft collection & 4 & $0.9 \%$ \\
Wound dehiscence & 4 & $0.9 \%$ \\
Utretric injury & 3 & $0.7 \%$ \\
Pseudoaneurysm & 2 & $0.5 \%$ \\
DVT & 1 & $0.2 \%$ \\
Postoperative hematoma & 1 & $0.2 \%$ \\
Intraoperative bleeding & 1 & $0.2 \%$ \\
\hline UTI = Urinary tract infection; & DVT = Deep vein thrombosis.
\end{tabular}

\section{DISCUSSION}

As compared to dialysis therapy, renal transplantation has noteworthy advantages, 1 in financial and psychological terms; but due to the shortfall of live-related donor availability, it has led to global increase in commercial transplantation programmes where recipients who need RRT, opt for LURRT and, therefore, they have to face several difficulties in terms of surgical and medical problems. ${ }^{11,12}$

This series highlights few areas of concern about renal transplants which were done outside Kuwait in various countries. Some previous studies showed that in these types of transplants, early postoperative mortality was high, while other studies also described high rate of late postoperative mortality. ${ }^{13}$ The one-year survival rate of overseas LURRT's may be between 80 - 90\%, compared with greater than $95 \%$ for Australian living-donor transplants. ${ }^{14}$ The early survival rate was better in this study and only $7(1.6 \%)$ patients expired due to various complications.

In case of surgical complications, in early transplant period, most patients have to undergo reoperation, which subsequently affects the graft survival. In this analysis, the authors found rate of surgical complications was high $(26.8 \%)$. In contrary to this, other studies showed a complication rate of $12.7 \%$ and $15.9 \%$, respectively. 15,16

Many times, the cause of the complications was not found, but to reduce the complications rate, the authors have to meet the accepted criteria of transplantation practice. Chugh and $\mathrm{Jha}^{7}$ from India reported that some of these LURRT were performed by inexperienced clinicians in their private clinics, which lacked the most basic hygienic facilities.

In regard to our surgical complications, we found lymphocele in around 6\% of the cases, which was treated surgically in most of the patients. Lymphoceles occur during the dissection process by opening the lymphatics. In most patients, these fluid collections are asymptomatic and are found on ultrasound examination not requiring any invasive treatment. Larger collections may be associated with dilation of the collecting system, pain, fever, and declined renal function. In these cases, ultrasound-guided aspiration should be done. Study done in Mexico showed a rate of lymphocele as $1 \% .15$ In this series, ureteral stenosis was found in $22(5.2 \%)$ patients. It was managed by ureteric reimplant in most of the cases. Contrary to this study, work done by Berger, Diamond and Sandhu and Patel showed ureteral obstruction at a rate of $2-10 \% .{ }^{17,18}$

Another common vascular complication is renal artery stenosis, which occurs in 3-23\% of all transplants in the first 12 months. ${ }^{19}$ This rate is associated with the end-toend anastomosis and cadaveric donor grafts. This complication should be entertained because if left unnoticed, it subsequently causes worsening of graft function and causes hypertension afterwards. ${ }^{20}$ Renal artery stenosis in $6(1.4 \%)$ patients which were treated by percutaneous transluminal angioplasty with stent placement. Chronic complications included incisional hernia in $14(3.3 \%)$ cases which were repaired with mesh.

Universally, the incidence of arterial thrombosis is $0.3-6.1 \% .{ }^{21}$ It is a disastrous complication and is most common in the first two weeks of transplantation, with $80 \%$ occurring in the first month and $93 \%$ in the first year. ${ }^{22}$ After the first month, thrombosis of the renal artery occurs mainly because of rejection or a high 
degree of stenosis. Graft thrombosis in $6(1.3 \%)$ patients, of whom 3 patients required graft nephrectomies.

Different investigators have different presumptions, some assume that most of the issues related to renal transplant are due to unsound donors and their imperfect hygienic conditions which further lead to wound infection, which was observed in $2.8 \%$ of the patients in our study, comparable to a study done by Reyna et al. 15

The most important area of concern is that when patients come back after renal transplantation for further management; there is a communication gap between the primary transplant team and the unit caring for the patients in Kuwait.

So with all these hurdles, for patients considering commercial LURRT, detailed knowledge should be given to these patients about the side effects profile and risk of graft loss; and if they decide to proceed with commercial transplantation, they should specifically ensure adequate documentation and communication of the transplant team who did the transplant with the future medical and surgical team so that early complications should be addressed and treated promptly.

\section{CONCLUSION}

Here single institution experience was described with LURRT done outside Kuwait, and the surgical complications associated with those transplants were highlighted. It was found that there were several issues with commercial transplantations, which should be addressed.

\section{REFERENCES}

1. McDonald SP, Russ GR. Survival of recipients of cadaveric kidney transplants compared with that receiving dialysis treatment in Australia and New Zealand 1991-2001. Nephrol Dial Transplant 2002; 17: 2212-9.

2. Winkelmayer WC, Weinstein MC, Mittleman MA, Ojo AO, Ettenger RE, Agodoa LY. Health economic evaluations: the special case of end-stage renal disease treatment. Med Decis Making 2002; 22: 417-30.

3. Wolfe RA, Ashby VB, Milford EL, Wolfe RA, Ashby VB, Milford EL, et al. Comparison of mortality in all patients on dialysis, patients on dialysis awaiting transplantation, and recipients of a first cadaveric transplant. N Engl J Med 1999; 341: 1725-30.

4. Cherry MJ. Kidney for sale by owner: human organs, transplantation, and the market. Washington: Georgetown University Press; 2000.
5. United States Renal Data System 1999 Annual Data Report. Am J Kidney Dis 1999; 34:S51-62.

6. Abouna GM. Negative impact of trading in human organs on the development of transplantation in the Middle East. Transplant Proc 1993; 25:2310-13.

7. Chugh KS, Jha V. Commerce in transplantation in third world countries. Kidney Int 1996; 49:1181-6.

8. Carpenter CB, Ettenger RB, Strom TB. Free Market approach to organ donation. N Engl J Med 1984; 310:395-6.

9. Frishberg $Y$, Feinstein S, Drukker A. Living unrelated (commercial) renal transplantation in children. J Am Soc Nephrol 1998; 9: 1100-3.

10. Morris PJ, Sells RA. Paying for organs from living donors 1985; Lancet 1:1510.

11. Mansy H, Khalil A, Aly TF, Filobbos P, Al-Dusari S, Al-Shareef Z. et al. Outcome of commercial renal transplantation: Two years follow-up. Nephron 1996; 74: 613-6.

12. Colakoglu M, Akpolat T, Arik N, Utas C, Arinsoy T, Sindel S, et al. Outcome of renal transplantation from foreign unrelated living donors in Turkey. Nephron 1995; 71:244-5.

13. Lei C, Abdullah K, Morad Z, Suleiman AB: Surgical complications of living unrelated kidney transplantations in a third-world country. Transplant Proc 1992; 24:1815.

14. Australia and New Zealand Dialysis and Transplant Registry. Available at:www.anzdata.org.au (accessed April 2004).

15. Reyna-Sepulveda F, Ponce-Escobedo A, Guevara CA, Escobedo-Villarreal M, Perez-Rodriguez E. Outcomes and surgical complications in kidney transplantation. Int $J$ organ Transplant Med 2017; 8; 78-84.

16. Eufrásio $\mathrm{P} 1$, Parada $\mathrm{B}$, Moreira $\mathrm{P}$, Nunes $\mathrm{P}$, Bollini $\mathrm{S}$, Figueiredo A, et al. Surgical complications in 2000 renal transplants. Transplant Proc 2011; 43:142-4.

17. Berger PM, Diamond JR. Ureteral obstruction as a complication of renal transplantation: A review. J Nephrol 1998; 11:20-3.

18. Sandhu C, Patel U. Renal transplantation dysfunction: the role of interventional radiology. Clin Radiol 2002; 57:772-83.

19. Libicher M, Radeleff B, Grenacher L, Hallscheidt P, Mehrabi A, Richer GM, et al. Interventional therapy of vascular complications following renal transplantation. Clin Transplant 2006; 20: 55-9.

20. Osman Y, Shokeir A, Ali-el-Dein B, Tantawy M, Wafa EW, el-Dein $A B$, et al. Vascular complications after live donor renal transplantation: study of risk factors and effects on graft and patient survival. J Urol 2003; 169: 859-62.

21. Obed A, Uihlein DC, Zorger N, Farkas S, Scherer MN, Krüger B, et al. Severe renal vein stenosis of a kidney transplant with beneficial clinical course after successful percutaneous stenting. Am J Transplant 2008; 8: 2173-6.

22. Merrill JP, Murray JE, Harrison JH, Guild WR. Successful homotransplantations of the human kidney between identical twins. J Am Med Assoc 1956; 160:277-82. 